\title{
Evolution of Coronavirus in Human Population: An Integrative Review
}

\author{
Hou Lu*, Dennis G. Caballes \\ a61522636@qq.com; dennis.caballes@ benilde.edu.ph \\ Centro Escolar University, Manila 1420, Philippines \\ De La Salle-College of Saint Benilde, Manila 1420, Philippines
}

\begin{abstract}
This is a constructive summary of the evolution of COVID 19 to the human population. In this review, the researchers tried to summarized the research conducted on the evolution of the coronavirus. The purpose of this review is to aggregate and summarized all researches conducted to examine the evolution of the Coronavirus in the human population utilizing the integrative review process. Integrative review research design was used and included articles from 2020 to 2021. Search terms such as "Evolution of coronavirus" and " " were used to identify scientific publications. Of 281 studies identified, 5 articles were included and rated using the Canadian Medical Association and Center for Evidence-Based Medicine Level of Evidence ranking system. The Coronavirus contained viral sub genomic messenger RNAs (sgmRNAs) which replicates in the respiratory tract. Cluster infections play a major role in the increase incidence of COVID 19. The infections were affected by factors that include containment measures and screening process. COVID 19. Clinical manifestations of COVID 19 mimic the respiratory problems in the neopediatric population
\end{abstract}

"Keywords: Coronavirus; evolution; human population; integrative review"

\section{Main text}

The World Health Organization (WHO) classified the rapidly growing coronavirus outbreak as a pandemic inMarch 2020. Since then, the number of those infected around the world has risen at an alarming rate. As of this writing, there are roughly 181.5 million confirmed cases of CoViD-19 worldwide, with 3.93 million deaths reported to WHO (2021). Certainly, the CoViD-19 pandemic has dramatically altered the lives of everyone. Strict enforcement of social distancing, mask-wearing, travel bans, and skeletal work schedules are just a few of the national governments' responses to mitigating the virus's spread (Ferrel, 2020, as cited by Agarwal \& Kaushik, 2020). Based on the ongoing global COVID-19 contagion, the WHO declared it a pandemic on March 11, 2020 as there is no safe place from its effects (McKay et al., 2020; WHO, 2020). The Coronavirus is spreading from continent to continent, which needs to be stopped to mitigate its impact to human population. This epidemic is giving people increased anxiety because of uncertainties of its future mitigation and treatment. This novel virus is new to the scientific world and many features of the virus are still not understandable due to its new strains (Qing and Gallagher, 2020). Hence, researchers around the world are in search of answers to understand the biological character and mode of spreading of the virus. A vast of articles and researches have been published since 2020 about the corona virus and its evolution to human population including epidemiology, pathogenesis, clinical characteristics and management of COVID 
19 (( Huang et al., 2020; Jin et al., 2020; Lai et al., 2020a; Lupia et al., 2020; Moriyama et al., 2020; Rodríguez-Morales et al., 2020; Rothan and Byrareddy, 2020; Shereen et al., 2020; Song and Karako, 2020; Vellingiri et al., 2020). However, the ongoing situation has urgently sought for a constructive summary of the evolution of COVID 19 to the human population. In this review, the researchers tried to summarized the research conducted on the evolution of the coronavirus. The purpose of this review is to aggregate and summarized all researches conducted to examine the evolution of the Coronavirus in the human population utilizing the integrative review process. This process is the most quick and scientific process to summarized articles been published in the different database. However, this study has also its limitations. Not all database was included in this integrative review process.

\subsection{Methodology}

The review used the integrative review design which included articles from 2020 to 2021. It is anchored in the research. question: "How did the CORONAVIRUS evolved in the human population?', After the research question was formulated, search terms, or descriptors, were identified. Search terms such as "evolution of coronavirus" and "COVID 19 in the human population" were used for the indexation of articles in the databases. Human population with the evolution of Coronavirus were taken as the population of the study. "evolution of Coronavirus", was selected as the research phenomenon. There were restrictions regarding studies that described evolution of coronavirus. It only focused on the evolution of coronavirus in the human population. There is no comparison was done in any studies since the COVID 19 was a new phenomenon that needs to be discovered in this time of pandemic. Studies that were included in the review explained many aspects of evolution such as genome types of COVID 19, symptoms of patients with COVID and the evolution of COVID 19 in cluster populations. The research design adapted the PRISMA flow diagram (Fig 1).

\subsection{Search Strategy}

The search strategy aimed to find all the relevant published studies. First, an initial limited search was undertaken using the Pubmed database. This was followed by an analysis of the text words contained in the title and abstract and of the index terms used to describe the article. A second search was undertaken in Google Scholar from the period of 2020 to 2021 using search keywords and the index terms identified, including "evolution of coronavirus" and COVID 19 in human population. The search period is critical to include recent and up-to-date literature and studies. The first and second searches used "AND" to combine the key word groups, whereas "OR" was used within each group of the key words. The searches were limited to English-language, peer-reviewed, and scholarly articles. Large databases including abstracts written in English-language, peer reviewed, and scholarly articles were considered to be of high standards of writing, content, and research quality. The reference lists of all identified reports and articles were screened to identify additional publications that might have been missed in the original and subsequent searches and might be relevant to this review purpose. 
Fig. 1: Prisma Diagram Showing the Articles used in the Review

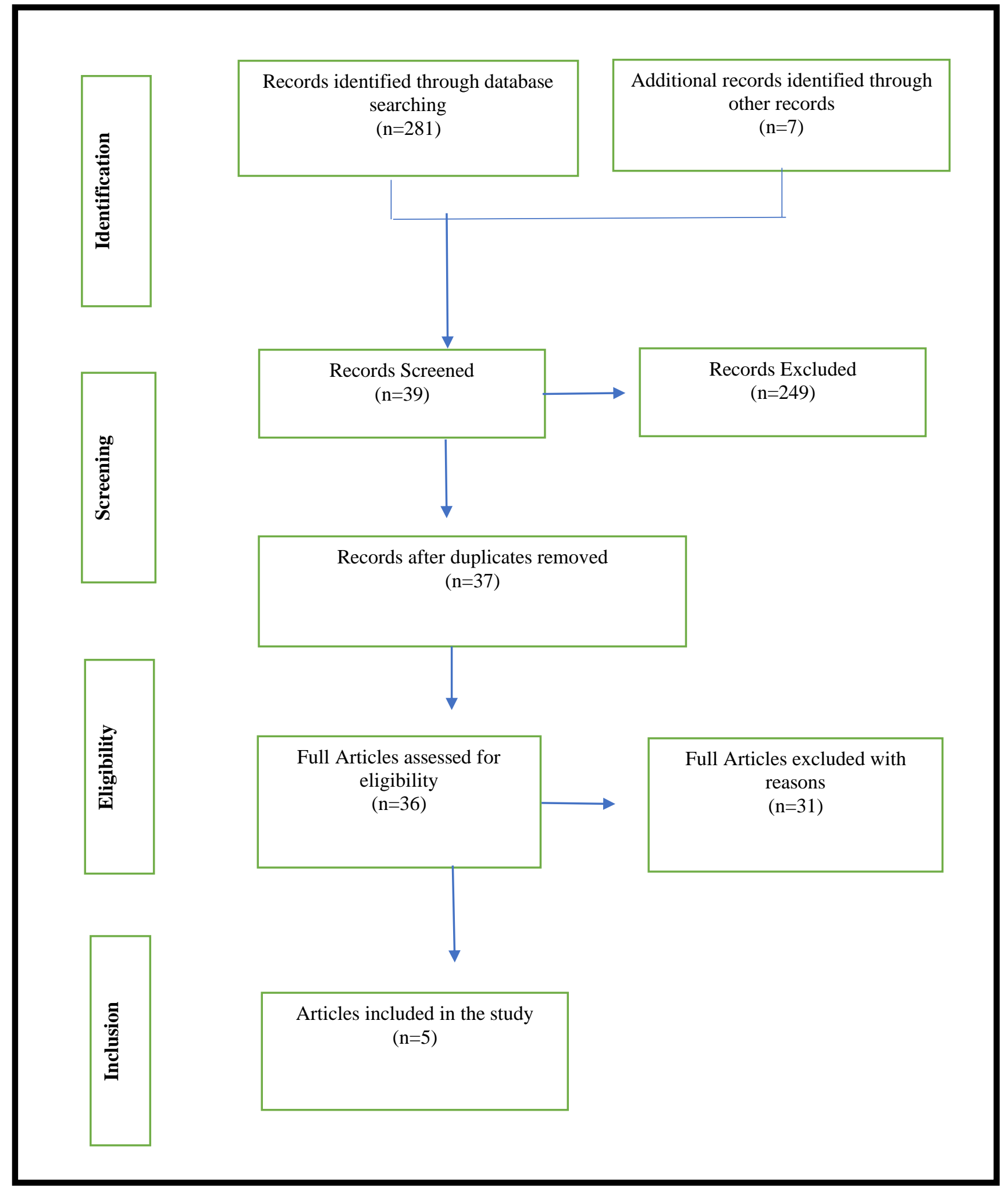




\section{Author Artwork}

The review consisted of five (5) articles. These were yielded from Pubmed database and web-based linkages such as Google. Because of the limitations of time and financial reasons, this review only utilized existing database that are free and available to the researcher. Out of the 281 only 5 are eligible for inclusion in the review. The 5 individual articles were then rated using the Canadian Medical Association and Center for Evidence-Based Medicine ranking system (Table 1).

Table 1: Tool used for Evidence-based ranking: Canadian Medical Association Center for Evidence-based Medicine Levels for the Evidence-Based Ranking System.

\begin{tabular}{|c|l|c|c|}
\hline Score & \multicolumn{1}{|c|}{ Level of Study } & $\begin{array}{c}\text { Relevant } \\
\text { Articles }\end{array}$ & Article Number \\
\hline 10 & Systematic/ metanalysis of RTC & 2 & 3,4 \\
\hline 9 & Large Sample RTC & 1 & 5 \\
\hline 8 & Small sample RTC & & \\
\hline 7 & Non-Random Controlled prospective studies & & 1,2 \\
\hline 6 & Non-Random Controlled Retrospective studies & 2 & \\
\hline 5 & Cohort studies & & \\
\hline 4 & Case-controlled studies & & \\
\hline 3 & Non controlled, descriptive studies & & \\
\hline 2 & Case studies & & \\
\hline 1 & Expert Consensus & & \\
\hline 0 & Anecdotes & 5 & \\
\hline & Total Articles & & \\
\hline
\end{tabular}

The studies included and selected for eligibility are systematic/ metanalysis process, with large sample RTC and non-randomized controlled retrospective study. Information of patients were the one used by the researchers. The results were used to formulate recommendations and conclusions. The other 249 articles were excluded because of the following reasons: (1) population (studies pertaining to zoonotic were excluded), (2) poor level of evidence, (3) small population size, (4) bias that was seen especially in the methodology, and (5) major methodological concerns.

\subsection{Results and Discussion}

The explanation of the 2019 NCov genome evolution and immune determinants of its proteome are vital to the control and preventive measures of COVID 19. Coronaviruses are single positive-stranded RNA viruses belonging to Coronaviridae family (Huang et al, 2020), which are divided into four genera: Alpha-, Beta-, Delta- and Gamma coronavirus.

In the review there were 2 studies discussed the COVID 19 genotypes. The work of Ramaiah and Arumugaswami (2020) and of Wang et al. 2021. The nCoV genotype have been evolved from a bat-CoV by accumulating non-synonymous mutations, indels, and recombination events. Structural proteins Spike (S), and Membrane (M) had extensive mutational changes, whereas Envelope (E) and Nucleocapsid (N) proteins were very conserved suggesting differential selection pressures exerted on 2019-nCoV during evolution (Ramiah \& Arumagaswani, 2020). While the study of Wang et al (2020), found out that the viral populations of patients contained a considerable proportion of viral sub genomic messenger RNAs (sgmRNAs), reflecting an active viral replication activity in the respiratory tract tissues. 
The trends in the incidence of the COVID 19 virus was investigated in four-French speaking country (Millimouno et al. 2021). The study found out that over the first six weeks of COVID-19, the incidence of the disease increased rapidly in Guinea which performed more screening tests than the other three countries. The factors explaining these results include the time of setting up and compliance with containment measures, and the screening approaches used by countries. Cluster infection plays a major role in the COVID 19 evolution and this was proved by the study of Liu et al. 2020. The study was conducted in China and the authors reported that seventy-two of the cluster infections were reported in this country. The major types of cluster infections were families, community transmission, nosocomial infection, gatherings, transportation, shopping malls, conferences, tourists, religious organizations, workers, prisons, offices, and nursing homes.

The last study reviewed the clinical evolution of cases of COVID 19 in neopediatric patients (Costa et al, 2020). The results of the review reported that the main clinical findings in this population were nasal congestion, fever, respiratory distress, diarrhea, fatigue, dry cough, increased C-reactive protein, leukopenia, lymphopenia, thrombocytopenia, elevated procalcitonin, bilateral groundglass opacity, pulmonary consolidation, and pneumonia.

This review resulted to the different part of the evolution process of COVID 19. It included review of studies that included genetic make up of COVID 19, Trends in the incidence and infection the role of cluster infection in the COVID 19 evolution and the explanation of the clinical findings for the neopediatrics population. There were a lot of reports of COVID 19 evolution available in the database, however the reports or studies does not merit scientific evidence because most of the studies are only review of the articles presented. This review is limited only to what was explained on the studies and articles included and is limited only to 2 database that was used by the researcher. Thus, the results of this review is only applicable to the database used such as Pubmed and google chrome.

\subsection{Implications for Research, Education and Practice}

The review is important to add in the present scientific evidences for COVID 19 evolution. The synthesis and findings are yielded from scientific studies that was retrieved from two (2) database. The findings are also applicable to education as additional literature in the conduct of future study for COVID 19. Further, the findings of this study also give merit to the prevention and management of COVID 19.

\subsection{Conclusion}

The Coronavirus contained viral sub genomic messenger RNAs (sgmRNAs) which replicates in the respiratory tract. Cluster infections play a major role in the increase incidence of COVID 19. The infections were affected by factors that include containment measures and screening process. COVID 19. Clinical manifestations of COVID 19 mimic the respiratory problems in the neopediatric population. 


\section{References}

Agarwal, S., \&amp; Kaushik, J. S. (2020). Student's Perception of Online Learning during COVID Pandemic. The Indian Journal of Pediatrics, 87(7), 554-554. doi:10.1007/s12098-020-03327-7

Costa TMS, Santos KVG, Rocha RRA, Oliveira ES, Dantas RAN, Dantas DV. Clinical evolution of cases of COVID-19 infection in neopediatrics: a scoping review. Rev Bras Enferm. 2021;74(Suppl 1):e20200662. doi: http://dx.doi.org/10.1590/0034-7167-20200662

Huang et al. 2020. Clinical features of patients infected with 2019 novel coronavirus in Wuhan, China. The Lancet (2020) DOI:https://doi.org/10.1016/S0140-6736(20)30183-5

Huang, C., Wang, Y., Li, X., Ren, L., Zhao, J., Hu, Y., et al., 2020a. Clinical features of patients infected with 2019 novel coronavirus in Wuhan, China. Lancet 395, 497-506. https:// doi.org/10.1016/S0140-6736(20)30183-5.

Jin, Y., Yang, H., Ji, W., Wu, W., Chen, S., Zhang, W., et al., 2020. Virology, epidemiology, pathogenesis, and control of COVID-19. Viruses 12, 372 .

Lai, M.M.C., Cavanagh, D., 1997. The Molecular Biology of Coronaviruses. In: Maramorosch, K., Murphy, F.A., Shatkin, A.J. (Eds.), Advances in Virus Research. 48. Academic Press, pp. 1-100

Liu, T. Gong, D Xiao, J. Hu, J. He, G. Rong, Z. \& Ma, W. (2020). Cluster infections play important roles in the rapid evolution of COVID-19 transmission: A systematic review. International Journal of Infectious Diseases 99 (2020). 374-380.

Lupia, T., Scabini, S., Mornese Pinna, S., Di Perri, G., De Rosa, F.G., Corcione, S., 2020. 2019 novel coronavirus (2019-nCoV) outbreak: a new challenge. J. Global Antimicrob. Resist. 21, 22-27. https://doi.org/10.1016/j.jgar.2020.02.021.

McKay, B., Calfas, J., T, A., 2020. Coronavirus Declared Pandemic by World Health Organization

Millimouno, T, Ahmed,M.A. Ly, B. Delamou, A. Sana, B. Faye, C. \& Damme, W. (2021). Evolution of the COVID-19 pandemic over six weeks in four French-speaking countries in West Africa. 2021 • Vol. 11 • 03008. doi: 10.7189/jogh.11.03008.

Moriyama, M., Hugentobler, W.J., Iwasaki, A., 2020. Seasonality of respiratory viral infections. Annu. Rev. Virol. https://doi.org/10.1146/annurev-virology-012420-022445

Qing, E., Gallagher, T., 2020. SARS coronavirus redux. Trends Immunol. 41, 271-273. https://doi.org/10.1016/j.it.2020.02.007.

Ramaiah, A. \& Arumugaswami, V. (2020). Insights into Cross-species Evolution of Novel Human Coronavirus 2019-nCoV and Defining Immune Determinants for Vaccine Development. https://doi.org/10.1101/2020.01.29.925867.

Rodríguez-Morales, A.J., MacGregor, K., Kanagarajah, S., Patel, D., Schlagenhauf, P., 2020. Going global - travel and the 2019 novel coronavirus. Trav. Med. Infect. Dis. 33, 101578. https://doi.org/10.1016/j.tmaid.2020.101578.

Rodríguez-Morales, A.J., MacGregor, K., Kanagarajah, S., Patel, D., Schlagenhauf, P., 2020. Going global - travel and the 2019 novel coronavirus. Trav. Med. Infect. Dis. 33, 101578. https://doi.org/10.1016/j.tmaid.2020.101578.

Rothan, H.A., Byrareddy, S.N., 2020. The epidemiology and pathogenesis of coronavirus disease (COVID-19) outbreak. J. Autoimmun., 102433 https://doi.org/10.1016/j. jaut.2020.102433

Shereen, M.A., Khan, S., Kazmi, A., Bashir, N., Siddique, R., 2020. COVID-19 infection: origin, transmission, and characteristics of human coronaviruses. J. Adv. Res. 24, 91-98. https://doi.org/10.1016/j.jare.2020.03.005.

Song, P., Karako, T., 2020. COVID-19: real-time dissemination of scientific information to fight a public health emergency of international concern. Bio Sci. Trends 14, 1-2. https://doi.org/10.5582/bst.2020.01056.

Vellingiri, B., Jayaramayya, K., Iyer, M., Narayanasamy, A., Govindasamy, V., Giridharan, B., et al., 2020. COVID-19: a promising cure for the global panic. Sci. Total Environ. 725, 138277. https://doi.org/10.1016/j.scitotenv.2020.138277

Wang D, Wang Y, Sun W, Zhang L, Ji J, Zhang Z, Cheng X, Li Y, Xiao F, Zhu A, Zhong B, Ruan S, Li J, Ren P, Ou Z, Xiao M, Li M, Deng Z, Zhong H, Li F, Wang W-j, Zhang Y, Chen W, Zhu S, Xu X, Jin X, Zhao J, Zhong N, Zhang W, Zhao J, Li J and Xu Y (2021) Population Bottlenecks and Intra-host Evolution During Human-to-Human Transmission of SARS-CoV-2. Front. Med. 8:585358. doi: 10.3389/fmed.2021.585358

WHO Coronavirus (COVID-19) Dashboard. (2021). Retrieved 1 July 2021, from https://covid19.who.int/ 